\title{
THE REFLECTION OF EXERCISE ON THE NEW GENERATION
}

\author{
Monika Popova ${ }^{1}$, Martin Krustev ${ }^{1}$, Luiza Hadzieva ${ }^{1}$, Silvia Filkova ${ }^{2}$ \\ ${ }^{1}$ Student, Medical College, Medical University of Varna, \\ ${ }^{2}$ TRS Rehabilitation Therapist, Medical College, Medical University of Varna
}

\begin{abstract}
INTRODUCTION: Our health, tonus and overall well-being are in a constant relationship with a number of factors. One of the most important ones being, as evolution set it - physical activity. Unfortunately, in recent years the nature of our day-to-day life has changed for the worse as sedentary life has taken the place of the active one, even for the youngest. This tendency has led to an unheard of amount of overweight youngsters and such with an impaired metabolism.
\end{abstract}

AIM: Therefore, we set it as our goal to research the parents' opinion on the effect of increased physical activity on the general health condition, physical development and mood of their children.

MATERIALS AND METHODS: To get to the bottom of this worldwide problem, we prepared and conducted a survey. The answers we received showed us the parents' views of the effect of an increased amount of activity on their children's physical and mental health. The survey was aimed towards the parents of children between the ages of 7 and 12. In it, we asked a number of questions which cover the parents' view on exercise, the connection with their child and their willingness to discipline them towards a healthy lifestyle.

RESULTS: The results showed that there is a substantial number of children that have little to no physical activity, but fortunately the tendency is for parents to be willing to make the first step towards a healthier, more active lifestyle.

CONCLUSION: Sedentary life leads to an increasingly overweight and unhealthy society. Children should be guided towards an active way of living by their parents not only with words but with an example. New and upcoming sports are a good way to stimulate the children's attention towards exercise and with that to lead to a healthier society.

Keywords: exercise, movement, youngster, health, parents

Address for correspondence:

Monika Popova

Medical College

84 Tzar Osvoboditel Blvd

9000 Varna

e-mail:m.st.popova@abv.bg

Received: April 15, 2017

Accepted: November 28, 2017

\section{INTRODUCTION}

With modern technology coming in people's day-to-day life, physical activity and healthy eating habits has taken a step backwards. The new ways for children to have a good time are more and more sedentary. Sedentary life and the lack of physical activity are one of the main reasons why children develop chronic diseases, obesity and mental conditions $(1,2)$. It is of highest value for every parent that their chil- 
dren are healthy - both physically and mentally. This is the reason why it is crucial that parents know the psychophysical benefits of living actively.

While in a growth spurt phase, children need a balanced combination of physical activity and a healthy diet. According to Timmons (2007 and 2012) and Hills AP(2011) optimal activity will rebound to the prevention of obesity $(3,4,5)$. The encouragement of children to participate in sports activities benefits their confidence, social habits and skills.

Physically it contributes to weight control, reduces the events of chronic illnesses, if the child is suffering from one, and the risk of developing such diagnosis.

Prevention of diseases and the stimulation of a wholesome daily routine are the best way to insure a healthy new generation. This is why parents should be familiar with the topic and should take an active part in the search of activities for their youngsters (6, $7,8)$.

Parents' awareness of the values of exercise are also the premise of the adequate development of their young ones.

\section{AIM}

Therefore, we set it as our goal to research the parents' opinion on the effect of increased physical activity on the general health condition, physical development and mood of their children.

\section{MATERIALS AND METHODS}

With regard to all of the made above points we decided to hold an anonymous survey the purpose of which was to make it publicly known and clear that exercise is a vital part to a child's health. The questions were directed towards the parents' opinions on how a higher amount of exercise would affect their children's day-to-day life.

The subject were 105 parents of children between the ages of 7 and 12. The location of the research was on the territory of "Obshtinski Detski kompleks - Varna" and took place between the months of January and March.

The gathered data was processed through the statistical software IBM SPSS for Windows, v. 19.0 using descriptive statistics: frequency analysis of the quality variables - calculation of absolute and rela- tive frequencies. A graphic method was used to visualize the results.

\section{RESULTS}

The 105 parents were between the age of 30 and 50 . Their ratio by gender was $76(72.6 \%)$ men and 29 (27.6\%) women.

More than half of the surveyed had a Master's degree - $55.33 \%(n=56)$, a Bachelor's degree held $26.7 \%(n=28)$ and a high school degree was held by $20 \%(\mathrm{n}=21)$.

Children's age varied from 7 to 12 . Their gender ratio was $43.8 \%(n=46)$ boys and $56.2 \%(n=59)$ girls.

Results show that a substantial amount of the children were active - 77\% $(n=81)$, and $23 \%(n=24)$ did not exercise (Fig. 1).

\section{Not exercising $\square$ Exercising}

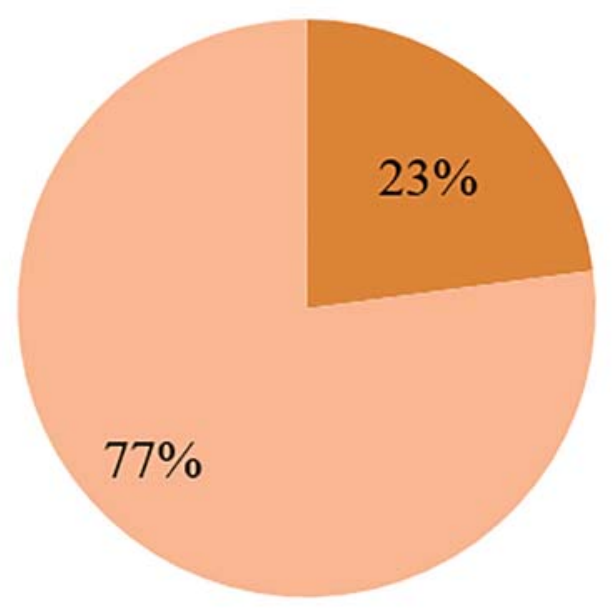

Fig. 1. Evaluation of children's participation in exercise

It is evident from this research that the numbers are split, with $48 \%$ of the physically active children being boys and $52 \%$ being girls. Regarding the children that did not exercise, the results showed that $71 \%$ of them were girls and $29 \%$ - boys (Fig. 2).

The margin between inactive children is due to the likelihood of girls' desire to enrich themselves more in educational aspects. To make a difference in the numbers of inactive girls, exercise has to be further implemented in theschool system. 


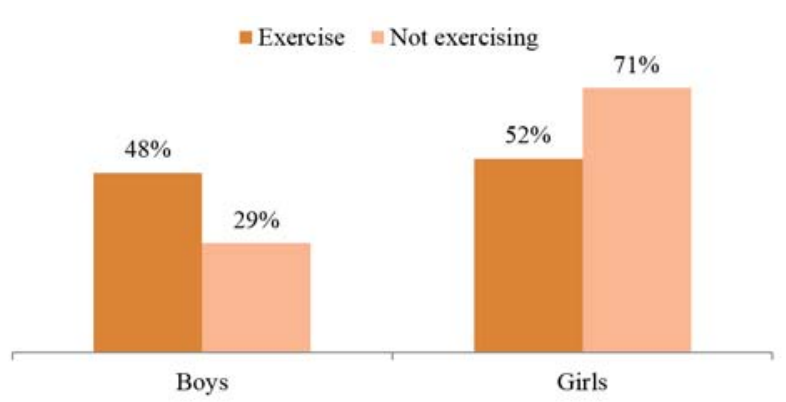

Fig. 2. Evaluation of children's participation in exercise by their gender

Regarding the value of sport in the life of the new generation there was a substantial difference with $77 \%$ of all parents stating that sport is an important part of their children's life and 23\% thinking the other way around (Fig. 3).

\section{$\square$ Of no importance $\square$ Important}

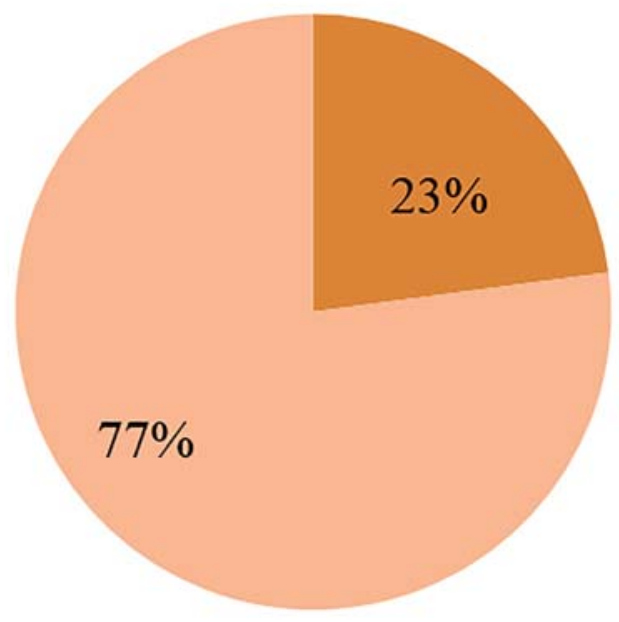

Fig. 3. Evaluation of parents' thoughts on the importance of exercise

Most parents acknowledge the important role of sport in their children's overall development. Physical activity enhances the blood flow, the metabolism and releases the built up stress from the body. Parents stating that sport is of no importance are most likely not familiar with all the benefits that it has to the human body in any aspect.

The survey shows the positive results that more and more parents find to spend practicing sports with their children. Only 5\% shared that they cannot find time. Nearly a third - 29\% of all the surveyed claimed that time is spent doing sports with their youngsters every day, $42 \%$ practiced three times a week and $24 \%$ - once a week (Fig. 4).

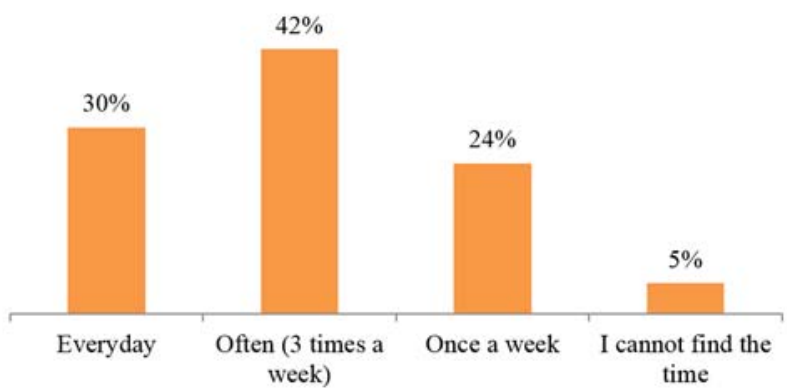

Fig. 4. Parents' time spent exercising with their children

Children are of highest priority to their parents. This is why most parents are able to find time to spend doing sports with their kids. Nevertheless, some cannot find the time as they are too busy with professional matters and have no spare time in their schedule.

Analysis of the opinion of the surveyed, shows that nearly half - $47 \%$ have let their child choose the type of sport they want to practice. This is common as it results in a more cheerful frame of mind. Adults chose the sport in $32 \%$ of the cases, it was based on a recommendation $-14 \%$ and by chance are only $7 \%$ (Fig. 5).

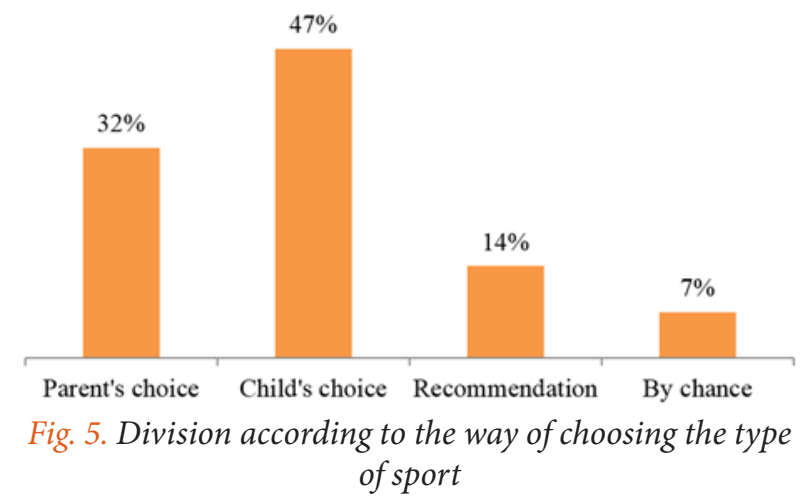

Due to the provided scope of self-selected activities, children are a lot more enthusiastic and cheerful while participating in their sport of choice. This 
way exercise not only affects the physical state of children but also their emotional state.

One of the most liked by youngsters sports is swimming, followed by judo and dancing (Table 1.)

Table 1. Sports preferred by children

\begin{tabular}{lcc}
\hline & Amount & Percent \\
\hline Swimming & 18 & $22.2 \%$ \\
Judo & 14 & $17.3 \%$ \\
Dancing & 12 & $14.8 \%$ \\
Ballet & 8 & $9.9 \%$ \\
Football & 6 & $7.4 \%$ \\
Rhythmic Gymnastics & 5 & $6.2 \%$ \\
Folk Dancing & 4 & $4.9 \%$ \\
Tennis & 3 & $3.7 \%$ \\
Gymnastics & 3 & $3.7 \%$ \\
Aikido & 2 & $2.5 \%$ \\
Handball & 1 & $1.2 \%$ \\
Karate & 1 & $1.2 \%$ \\
Synchronized Swimming & 1 & $1.2 \%$ \\
Table Tennis & 1 & $1.2 \%$ \\
Basketball & 1 & $1.2 \%$ \\
Overall & 81 & $100 \%$ \\
\hline \hline
\end{tabular}

The results which we acquired through our survey show that the percentage of healthy children is sufficiently high - 95\%, the remaining 5\% are chronically ill (Fig. 6).

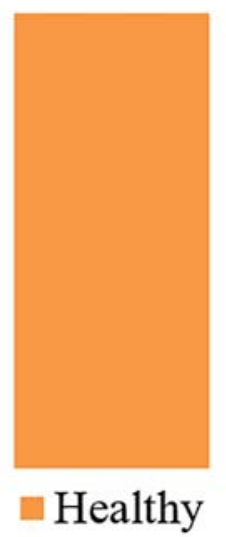

Fig. 6. Division according to the health condition of the children
The results are such, because most of the children of the parents, who took part in the survey, participate in sports. The chronically ill children are 5 from 105 interviewees. We do not deem the result as satisfactory. In order to lower the number of ill children, sports must be combined with a healthy diet, rest and dosed daily stress.

By the conducted survey we determined that most of the children have a feeling of happiness before a training session - 95\%, and afterwards - 99\%. Substantially lower is the percentage of children with a feeling of sadness $-5 \%$ before training and only $1 \%$ afterwards (Fig. 7).

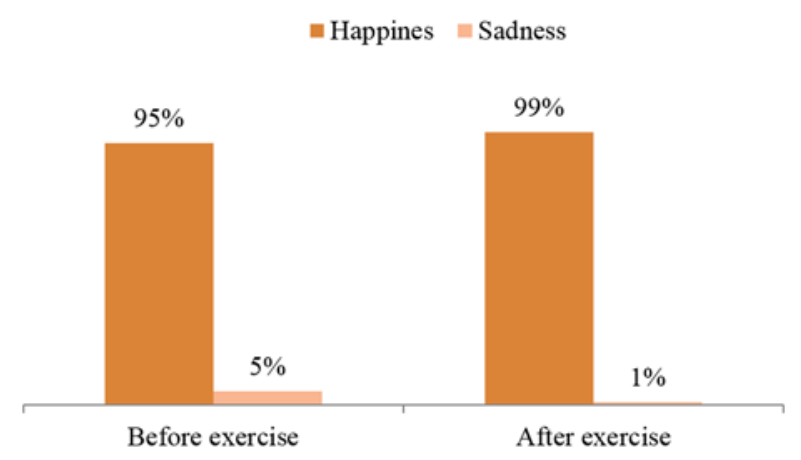

Fig. 7. Division according to the emotional state of the children

The given results are due to the impact of sport on the children. The physical activities energize, develop and create social contacts and thus valuable social skills for the children. The great number of happy children is also connected with the oportunity given to them to choose the sport, which they want to participate in. The percentage can be optimized by removing some of the stress factors, for example, setting tasks that exceed their physical potential.

\section{DISCUSSION}

A larger part of the children in our research do sports. The data we received regarding division of actively engaged in sports children according to their gender, is similar to those of a study by Gonzalo-Almorox E. and R.M. Urbanos-Garrido (2016), where it has been determined that girls $(24.2 \%)$ are slightly more physically active than boys (16.8\%) (9).

Parents' contribution is the most important factor for the physical activity as the children in the research are between the ages of 7 and 12. Parents re- 
alize that children who actively participate in sports are more cheerful and more confident and therefore most make an effort to motivate them in that direction. Regular training strengthens the body and improves the coordination and concentration, which contributes to succeeding in the academic sphere.

In a study by Sallis et al. (2000) it was determined that the level of physical activity is lower in cases of lacking support from parents and relatives (7). Studies so far show that children and adolescents are prone to be more active when their parents and friends are $(10,11,12)$, when they are encouraged to be (8) and are accompanied in physical activities $(7,10,11,13)$. This research shows that encouragement of physical activity by family and friends is crucial among young people. As the results are centered around the parents' influence, we studied their opinion and we included the following recommendations with the purpose of optimizing the physical activities.

Some of the parents shared recommendations with the purpose of improving their children's lives:

1. 'Participating in sports and a healthy diet depend on the organization of the family and not on the free time and income.' - Mother, Master's degree, 41-45 years old, boy - 7 years old, girl 11years old, gymnastics, aikido, basketball.

2. 'We want more free sports grounds in the city (and information about existing ones?).' Mother, Master's degree, 31-35 years old, girl - 7 years old, climbing.

3. 'Sports and outdoor activities must be included very actively in schools and kindergardens without necessarily striving for achievements. The personal example is very important.' - Mother, Bachelor's degree, 36-40 years old, boy -6 years old, girl - 9 years old, dancing, swimming.

4. '[We wish] for more education and discourses, and activities with the children regarding a healthy diet and sports.' - Mother, Master's degree, 36-40 years old, girl - 9 years old, not involved in sports.

\section{CONCLUSION}

An active lifestyle has health, emotional and social benefits. Most parents and their children do try to include sports activities in their daily lives. Despite this, not all parents have the opportunity to spend time engaging in physical activities as they are occupied professionally and do not have the free time to do it. The shared recommendations of parents once again demonstrate their willingness to promote the physical activity of their children.

\section{Conflict of Interest}

The authors declare no conflict of interest

\section{REFERENCES}

1. Bojkova A, Slavcheva-Hinkova P, Albert M, Study on the university students' opinion on their health and physical activity status. Health and Science. 2013; 3(4):5-9 (in Bulgarian).

2. Georgieva A, Dimitrova Cv. Impact of stress on first-year students from the Nurse program in the Medical University of Varna. Report Book - X National Student Session, 3-4.11.2011. Pleven: Publishing Centre MU-Pleven; 2012. p. 79-89.(in Bulgarian)

3. Hills AP, Andersen LB, Byrne NM. Physical activity and obesity in children. Br J Sports Med. 2011; 45(11): 866-70. doi: 10.1136/bjsports-2011-090199

4. Timmons BW, Naylor PJ, Pfeiffer KA. Physical activity for preschool children-how much and how? Can J Public Health. 2007;98(Suppl. 2):122-34.

5. Timmons BW, Leblanc AG, Carson V, Connor Gorber S, Dillman C, Janssen I, et al. Systematic review of physical activity and health in the early years (aged 0-4 years). Appl Physiol Nutr Metab. 2012; 37(4): 773-92. doi: 10.1139/h2012-070

6. Gruber K, Haldeman L. Using the family to combat childhood and adult obesity. Prev Chronic Dis. 2009; 6(3): A106

7. Sallis JF, Prochaska JJ, Taylor WC. A review of correlates of physical activity of children and adolescents. Med Sci Sports Exerc. 2000; 32(5): 963-75.

8. Trost SG, Sallis J, Pate RR, Freedson PS, Taylor W, Dowda M. Evaluating a model of parental influence on youth physical activity. Am J Prev Med. 2003; 25(4):277-82.

9. Gonzalo-Almorox E, Urbanos-Garrido RM. Decomposing socio-economic inequalities in leisure-time physical inactivity: the case of Spanish children. Int J Equity Health. 2016;15(1):106. doi: 10.1186/s12939-016-0394-9 
10. Davison KK, Cutting TM, Birch LL. Parents' activity-related parenting practices predict girls' physical activity. Med Sci Sports Exerc. 2003:35(9): 1589-95. doi: 10.1249/01.MSS.0000084524.19408.0C

11. Davison KK. Activity-related support from parents, peers and siblings and adolescents' physical activity: Are there gender differences? J Phys Act Health. 2004, 1(4): 363-76. doi: 10.1123/jpah.1.4.363

12. Saxena R, Borzekowski DLG, Rickert VI. Physical activity levels among urban adolescent females. J Pediatr Adolesc Gynecol. 2002; 15(5): 279-84.

13. Hoefer WR, McKenzie TL, Sallis JF, Marshall SJ, Conway TL. Parental provision of transportation for adolescent physical activity. Am J Prev Med. 2001;21(1): 48-51. 